Butler University

From the SelectedWorks of Travis J. Ryan

Spring May, 2017

Influence of Light Quality and Quantity on Heterophylly in the Aquatic Plant Nymphaea odorata subsp. tuberosa (Nymphaeaceae)

Travis J. Ryan 


\section{Influence of Light Quality and Quantity on Heterophylly in the Aquatic Plant Nymphaea odorata subsp. tuberosa (Nymphaeaceae)}

Author(s): Shelley A. Etnier, Philip J. Villani and Travis J. Ryan

Source: Northeastern Naturalist, 24(2):152-164.

Published By: Eagle Hill Institute

https://doi.org/10.1656/045.024.0205

URL: http://www.bioone.org/doi/full/10.1656/045.024.0205

BioOne (www.bioone.org) is a nonprofit, online aggregation of core research in the biological, ecological, and environmental sciences. BioOne provides a sustainable online platform for over 170 journals and books published by nonprofit societies, associations, museums, institutions, and presses.

Your use of this PDF, the BioOne Web site, and all posted and associated content indicates your acceptance of BioOne's Terms of Use, available at www.bioone.org/page/ terms of use.

Usage of BioOne content is strictly limited to personal, educational, and non-commercial use. Commercial inquiries or rights and permissions requests should be directed to the individual publisher as copyright holder. 


\title{
Influence of Light Quality and Quantity on Heterophylly in the Aquatic Plant Nymphaea odorata subsp. tuberosa (Nymphaeaceae)
}

\author{
Shelley A. Etnier ${ }^{1, *}$, Philip J. Villani ${ }^{1}$, and Travis J. Ryan ${ }^{1}$
}

\begin{abstract}
Heterophylly, the production of different leaf forms on the same plant, is a widespread phenomenon in terrestrial and aquatic plants and provides an opportunity to study how sessile organisms sense and respond to changes in environmental factors. Nymphaea odorata subsp. tuberosa (American White Water Lily) produces 2 distinct leaf forms: a floating surface leaf and an aerial form in which the lamina is held above the water. Previous research suggests that changes in the light environment may be a critical determinant of heterophylly in Nymphaea. In this study, we tested the hypothesis that changes in light quantity and light quality stimulate the production of aerial leaf forms in water lilies. Specifically, shade cloth was used to reduce light intensity (quantity), and varying plant densities were used to increase leaf cover (affecting light quality) in artificial ponds. Aerial leaf production was not stimulated by reduction in light quantity alone but was when leaf cover exceeded $30-40 \%$. We suggest that as the surface of a pond becomes covered with a canopy of leaves, American White Water Lily responds with the production of aerial leaves that rise above the surface of the water to gain access to light. Interestingly, water lilies exhibit an atypical shade response in that aerial leaves have short, thick petioles that allow them to rise above the surface of the water, rather than displaying the elongated phenotype associated with etiolation, which is the typical shade response of other flowering plants.
\end{abstract}

\section{Introduction}

Heterophylly, or the production of multiple leaf types on a single plant, is a widespread phenomenon in both terrestrial and aquatic plants. In aquatic environments, heterophylly typically occurs when a plant grows in 2 physically dissimilar environments (e.g., terrestrial and aquatic) that present dramatically different physical and physiological challenges to different parts of the plant. Numerous studies have investigated the causal factors leading to heterophylly in aquatic plants. These factors include red/far-red ratios, photoperiod, light intensity, water depth, levels of $\mathrm{dO}_{2} / \mathrm{dCO}_{2}$, osmotic stress, temperature, and desiccation (Anderson 1982, Bristow 1969, Deschamp and Cooke 1984, Goliber and Feldman 1989, Johnson 1967, Kuwabara et al. 2003; for reviews, see Franklin 2008, Wells and Pigliucci 2000). In some cases, heterophylly results from a combination of environmental factors, rather than any single cue (Franklin 2008, Vandenbussche et al. 2005).

Nymphaea odorata Ait. subsp. tuberosa (Paine) Wiersema \& Hellquist (American White Water Lily) exhibits marked heterophylly. Plants can produce 2 distinct mature leaf forms (Sculthorpe 1967) that differ in their position relative to the

\footnotetext{
${ }^{1}$ Department of Biological Sciences, Butler University, Indianapolis, IN 46208. *Corresponding author - setnier@butler.edu.
}

Manuscript Editor: Thomas Philbrick 
surface of the water: the most common leaf type floats on the surface of the water, whereas the lamina of the alternative leaf type is held above the surface of the water. These 2 forms can exist simultaneously on a single plant, but aerial forms are only produced under certain conditions (Villani and Etnier 2008). In the situation where aerial leaves are produced, surface leaves predominate at the beginning (May and June in central Indiana) and end (September) of the growing season, and aerial leaves predominate during the middle (Villani and Etnier 2008). Interestingly, these different leaf forms do not reflect the growth continuum of a single leaf. Rather, an individual mature leaf has either a surface lamina or an aerial lamina (Villani and Etnier 2008). There are minor differences in these 2 leaf forms (Sculthorpe 1967). The surface area of aerial leaves tends to be larger (Villani and Etnier 2008), and our personal observations suggest that the aerial lamina is more structurally robust. Anatomically, stomata are only located on the upper surface of the lamina regardless of its position relative to the water (Sculthorpe 1967).

While the mature laminae are relatively similar, the petioles of aerial and surface leaves can be differentiated morphologically early in development. Aerial leaves have a significantly larger petiole diameter as they emerge from the sediment at the bottom of the pond (Villani and Etnier 2008). This early morphological differentiation suggests that the site of stimulus perception is underwater at the rhizome tip and/or in developing leaves, but it is unclear which factor(s) are responsible for triggering different developmental pathways during leaf formation.

The seasonal changes in the proportion of surface and aerial leaves suggest that the factor(s) influencing their production may also vary seasonally. A previous field study in central Indiana indicates that temperature, $\mathrm{dO}_{2}$, and $\mathrm{dCO}_{2}$, while highly variable from day to day, oscillate above and below a central mean across the growing season, suggesting that they are not associated with the observed heterophyllic variation; additionally, ammonia concentration and water $\mathrm{pH}$ remained nearly constant across the growing season, also eliminating them as possible signals (Etnier and Villani 2008). While the specific factors influencing the production of surface and aerial leaves in Nymphaea are unknown, crowding (and thus competition for light) may play an important role (Sculthorpe 1967, Villani and Etnier 2008). As noted above, leaf production, and hence the competition for light, is strongly seasonal in central Indiana ponds. A dense canopy of leaves, whether in a terrestrial or aquatic system, will affect both light quantity and quality (red/far-red ratio) as specific wavelengths are absorbed (Salles et al. 1995, Smith and Whitelam 1997, Leyser and Day 2003). Both of these factors have been shown to influence heterophylly in diverse aquatic species, including Proserpinaca (marsh mermaid weed), Porphyra (a red algae), and Marsilea (an aquatic fern) (Goliber and Feldman 1989, Leyser and Day 2003, Lin and Yang 1999, Monroe and Poore 2005, Salles et al. 1995, Schmidt and Millington 1968, Smith and Whitelam 1997). In a prior field experiment, we observed that controlled maintenance of open water at the surface of a pond completely repressed the appearance of aerial leaf forms in Nymphaea (Villani and Etnier 2008). In contrast, aerial leaves appeared if the surface leaves were allowed to form a dense canopy on the water's surface (Villani and Etnier 2008), 
thus limiting light penetration to the rhizome and developing leaves. We hypothesized that the open water permits more natural light irradiance to penetrate to the underlying rhizomes, which signals for the production of surface leaves, whereas a canopy of surface leaves alters the underwater light environment and stimulates the production of aerial leaves.

In this study, we tested the hypothesis that changes in the underwater light environment over the growing season stimulate the production of aerial leaf forms in water lilies. Specifically, we were interested in the impact of the competition for light and the resultant changes in underwater light intensity and light quality that might impact individual leaf development. Results from 2 field seasons provided information on the relative impact of light intensity and light quality on heterophyllic growth patterns American White Water Lily.

\section{Materials and Methods}

\section{Plant material}

Plants were collected in June 2007 from a population of American White Water Lily growing in a $2000-\mathrm{m}^{2}$ pond at Eagle Creek Park $\left(39^{\circ} 52^{\prime} 3^{\prime \prime} \mathrm{N}, 86^{\circ} 18^{\prime} 1 " \mathrm{~W}\right)$ in Indianapolis, IN. Tuberous rhizomes were collected and established in two 1000-L water-filled polyethylene tanks in an unshaded area on Butler University's campus during the summer of 2007. In May 2008, pieces of rhizome $\sim 10 \mathrm{~cm}$ in length were removed from established plants, transferred to 3-gallon plastic pots, and covered with $\sim 15 \mathrm{~cm}$ of potting soil. Pea-sized gravel was placed over the soil to help maintain the position of the rhizome in the pot. Pots were submerged and overwintered in the same large tanks. These plants were used during both field seasons, as described below.

\section{Field season 1 (summer 2008)}

We used a randomized block design to test whether light intensity and/or light quality serves as the signal for the appearance of aerial leaves. We transferred potted plants to 375 -L Rubbermaid ${ }^{\circledR}$ stock tanks that served as artificial ponds. The tanks had a surface area of $\sim 0.8 \mathrm{~m}^{2}$ (oval tanks approximately $1.2 \mathrm{~m} \mathrm{x} 0.8 \mathrm{~m}$ ), with a water depth of $\sim 0.5 \mathrm{~m}$. Plant density was the main experimental variable, with 1 , 2 , or 4 plants ( 1 per pot) per tank. Increased plant density should increase biotic shading, thus impacting both the quality (red/far-red ratio) and quantity of light available to the plants. The second variable was the presence or absence of abiotic shading, which should alter only the intensity, but not the quality, of light. We used $50 \%$ neutral shade cloth (as rated by the manufacturer) mounted $24 \mathrm{~cm}$ above the surface of the water on structures built from $2.5-\mathrm{cm}$ PVC pipe to shade the tanks. The combination of crowding and shading resulted in 6 treatment combinations that were replicated 4 times each for a total of 24 experimental units. We positioned tanks in a grid with 4 rows and 6 columns in an open field with $\sim 1 \mathrm{~m}$ between each tank. Each row consisted of a complete set of treatment combinations, with the exact position of each treatment determined randomly. This approach was used to insure that all tanks received similar light exposure over the course of a day. 
We treated each tank with algaecide (Green Clean Granular Algaecide, BioSafe Systems, LLC, East Hartford, CT) on May 16 and May 22 to limit the competition for light from other biotic sources.

\section{Field season 2 (summer 2009)}

During this field season, we more closely examined the influence of light quality on water lily heterophylly, again using a randomized block design. In field season 1, the use of shade cloth was associated with increased leaf cover without the production of aerial leaves (see Results section for statistical analysis). Thus, during field season 2, all stock tanks were covered with $50 \%$ shade cloth to enhance leaf cover. We did not control for the presence or absence of algae in field season 2, as our goal was to increase biotic shading. For this growing season, plant density was the main variable; we randomly assigned stock tanks either 2 or 5 plants. The second variable was the presence or absence of other competing plants. For the competing plants treatment, we seeded tanks with $\sim 1 \mathrm{~L}$ of mixed aquatic plants that were added after surface leaves appeared in early June. These plants were collected from the same natural pond from which we obtained the original lily plants. This 2 x 2 experimental design yielded 4 treatment combinations that were replicated 4 times for a total of 16 experimental units. As in field season 1, we arranged the tanks in a grid, with each row containing all treatment combinations in a randomized distribution.

\section{Leaf counts and cover analysis}

Data collection began as soon as water lily plants started producing leaves in early to mid-June. We counted the number of aerial and surface leaves twice a week throughout the growing season, from about the start of June through the end of September. Surface leaves were counted only if they were $>5 \mathrm{~cm}$ in diameter (smaller leaves were present, but were relatively rare and thus not counted). Every 2 weeks, we estimated how much of the water's surface was covered by surface leaves (proportion leaf cover). This measure included all water lily leaves, regardless of size, but did not factor in leaves from other aquatic plants. To estimate leaf cover, we constructed a rectangular frame made of PVC pipe measuring $120 \mathrm{~cm}$ x $80 \mathrm{~cm}$. This frame was subdivided into an $8 \times 12$ grid of square sections, delineated with string, with each square measuring $10 \mathrm{~cm}$ x $10 \mathrm{~cm}$. We placed the grid over each tank and coded each square on a scale of $0-4$ depending on the density of leaf cover (numbers corresponding to $0 \%, 25 \%, 50 \%, 75 \%$, or $100 \%$ cover, respectively). Note that this measure included all surface leaves regardless of size. Because the tanks were oval and our grid was rectangular, 32 of 96 squares overlapped the edges of the tanks and could have a maximum of only $50 \%$ cover (and thus a maximum score of 2). After coding all of the squares, we added these numbers together and divided by the total possible number ( 352 when corrected for the partial squares) to estimate the proportion of the water surface covered with leaves.

\section{Light measurements}

We measured light intensity (photosynthetically active radiation [PAR]) and quality of light (red/far-red ratio) weekly during the growing season (early June 
through mid-September) between 12:00 and 13:00 hours. Light intensity ( $\mu$ mol $\mathrm{m}^{-2} \mathrm{sec}^{-1}$ ) was measured with a field photometer (Quantum Scalar Laboratory PAR Irradiance Sensor, Biospherical Instruments, Inc., San Diego, CA), while the red/ far-red ratio was measured with a red/far-red light meter (Fieldscout, Spectrum Technologies, Inc., Elysburg, PA). PAR was first measured in the open air to determine overall light intensity, which may vary both seasonally and daily. We then measured both light intensity and light quality in the tanks themselves at the depth of a developing rhizome, $\sim 40 \mathrm{~cm}$ underwater. We collected PAR measurements in open, sunlit water, to determine the effects on light parameters of water alone, as well as under the shade cloth, and collected red/far-red measurements in open water, in water under the shade cloth, and also in the shade under a single leaf to determine how the ratio was affected by light passing through water, shade cloth, and biotic materials. Single PAR measurements were recorded, whereas red/far-red measurements were taken 3 times and averaged to provide a value for daily light quality. For consistency, recorded values reflect measurements taken in tanks with only 2 plants, although the actual number of plants should not have an impact on the measurements.

\section{Data analysis}

In field season 1, no aerial leaves were produced regardless of the treatment. For the data from field season 1, we used 2-way analysis of variance (ANOVA) with proportion of the water surface covered with leaves (hereafter referred to as "leaf cover") as a response variable to test the effects of lily density and the presence of shade cloth. For field season 2, we used 2-way ANOVA with leaf cover as a response variable to test the effects of lily density and the presence of competing surface plants. Maximum leaf cover was used in all data analyses because it was under this condition that the difference in light availability to the developing leaves was at its most extreme. In field season 1, that date was approximately 15 July for all treatments, while it was slightly more variable during field season 2 . We then used a 1-way ANOVA to determine whether leaf cover differed in tanks that produced one or more aerial leaves from those that did not. Finally, we used simple linear regression to determine whether the number of mature surface leaves affected the surface area covered. In all analyses, we arcsine-transformed leaf cover and inverse-transformed the number of mature surface leaves to meet the assumptions of parametric tests.

\section{Results}

\section{Experimental variables}

As expected, treatment of American White Water Lily plants with 50\% shade cloth reduced overall light intensity (Table 1), although daily light-intensity data differed considerably among dates due to variable cloud cover (Fig. 1). For example, on 6 June 2008 in an unshaded tank, the mean underwater PAR was 581.25 $\mu \mathrm{mol} \mathrm{m} \mathrm{sec}^{-1}$, while the value was $277 \mu \mathrm{mol} \mathrm{m}^{-2} \mathrm{sec}^{-1}$ in a shaded tank, representing a $48 \%$ reduction in light intensity due to the shade cloth. Similar reductions in 
light intensity were obtained on an overcast day (6 July), with a $52 \%$ reduction in light intensity under the shade cloth. This same general trend is seen when looking at the mean values for field season 1, where the presence of shade cloth reduced the light intensity by $46 \%$ (Table 1). Changes in underwater light intensity were also evident across the growing season (Fig. 1). In general, underwater light intensity decreased in all treatments from the start of the monitoring period until late July. Underwater light intensity then remained relatively constant for $\sim 1$ month (August) and subsequently began to rise again until the end of the monitoring period

Table 1. A comparison of light parameters between field seasons 1 and 2. Light intensity was measured weekly from June to September (season $1 n=11$; season $2 n=14$ ) in 4 replicate tanks containing 2 plants per tank. Light intensity, for both shade and no shade, was measured underwater at the level of the rhizome; shade was generated using a 50\%-reduction shade cloth. Light intensity was measured in PAR $\left(\mu \mathrm{mol} \mathrm{m} \mathrm{mec}^{-1}\right)$. Standard deviation is in parentheses.

\begin{tabular}{llccc} 
Season & Statistic & Open air & Water and shade & Water and no shade \\
\hline 1 & Mean (SD) & $2014(545)$ & $190(80)$ & $415(161)$ \\
& Max. & 2569 & 280 & 679 \\
& Min. & 890 & 162 & 200 \\
2 & Mean (SD) & $2098(595)$ & $216(118)$ & \\
& Max. & 3468 & 494 & \\
& Min. & 772 & 77 & \\
\hline
\end{tabular}

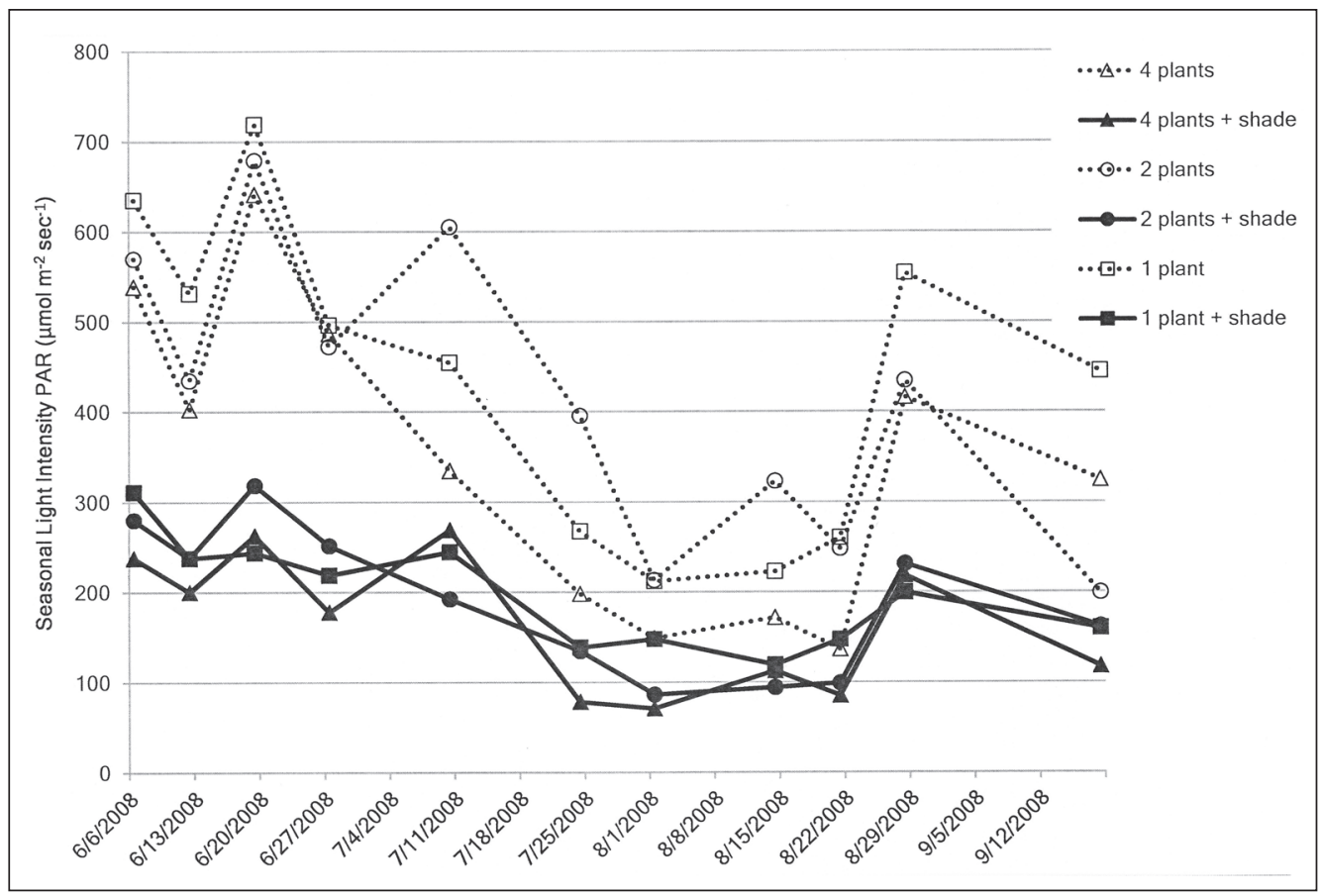

Figure 1. Measures of seasonal light intensity under a lily pad leaf canopy during field season 1 . Treatments included 4, 2, and 1 plants per tank. Treatments were either in full sun or under $50 \%$ shade cloth (+ shade). 
(September) (Fig. 1). Decreasing light intensities (Fig. 1) roughly coincided with higher leaf cover (Fig. 2). In general, these same general trends were seen in field season 2 (in which all tanks were covered in shade cloth to promote leaf production). Average seasonal light intensity was similar in both seasons, as was the average light intensity under the shade cloth (Table 1).

The red/far-red ratios measured underwater in the open sunlight water and under the shade cloth were similar to typical values measured in the air (Fig. 3). In contrast, the ratio was reduced under the canopy of surface leaves and was comparable to shade values recorded under a leaf canopy in both terrestrial (Franklin 2008) and aquatic systems (Salles et al. 1995, Vandenbussche et al. 2005). Recorded values were also similar to those measured in a natural field setting. For example, on 24 June 2008 in a pond at Eagle Creek Park, Indianapolis, IN (the original source of experimental plants), the red/far-red ratio below surface leaves was $0.29 \pm 0.08$ $(n=3)$, while the red/far-red ratio in the open water was $1.30 \pm 0.005(n=3)$.

\section{Plant growth}

During both field seasons, the timing and patterns of leaf production were generally comparable to previous observations from a natural pond (Villani and Etnier

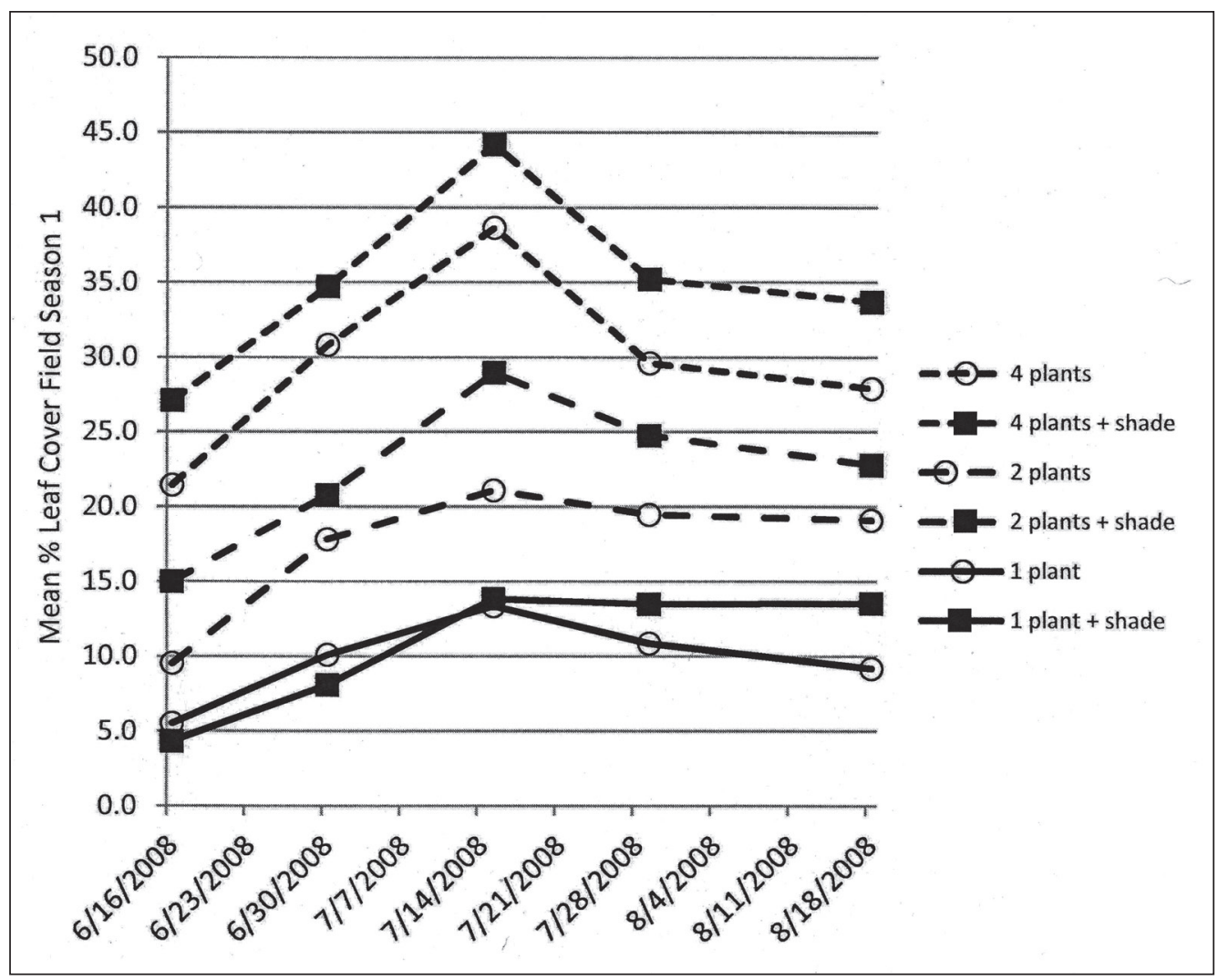

Figure 2. Mean percent cover of surface water with lily pad leaves among treatments with 4,2 , or 1 plants per tank during field season 1 . Treatments were either in full sun or under $50 \%$ shade cloth (+ shade). Standard deviations were omitted for visual clarity. 
2008). The plants appeared healthy, with all treatments producing flowers from approximately early June until the end of July. The one observed difference was that overall leaf production and leaf cover in the tanks did not reach the same levels seen in a natural setting, where leaf cover approaches $100 \%$ late in the growing season (Villani and Etnier 2008). In all treatments, the number of surface leaves increased rapidly early in the growing season, remained fairly stable during the middle of the growing season, and gradually (compared to earlier in the growing season) decreased toward the end of the growing season. In field season 1, we found that both the density of plants and the presence of shade cloth had a significant effect on the maximum percentage of area covered by large surface leaves (2-way ANOVA with percentages arcsine-transformed: density $F_{2,18}=80.59, P<0.0001$; shade $F_{1,18}=$ 5.96, $P=0.0252$; interaction $F_{2,18}=1.46, P=0.2579$ ). In field season 2 , maximum leaf cover occurred in tanks with 5 plants, with coverage exceeding $45 \%$ for brief periods (Fig. 4).

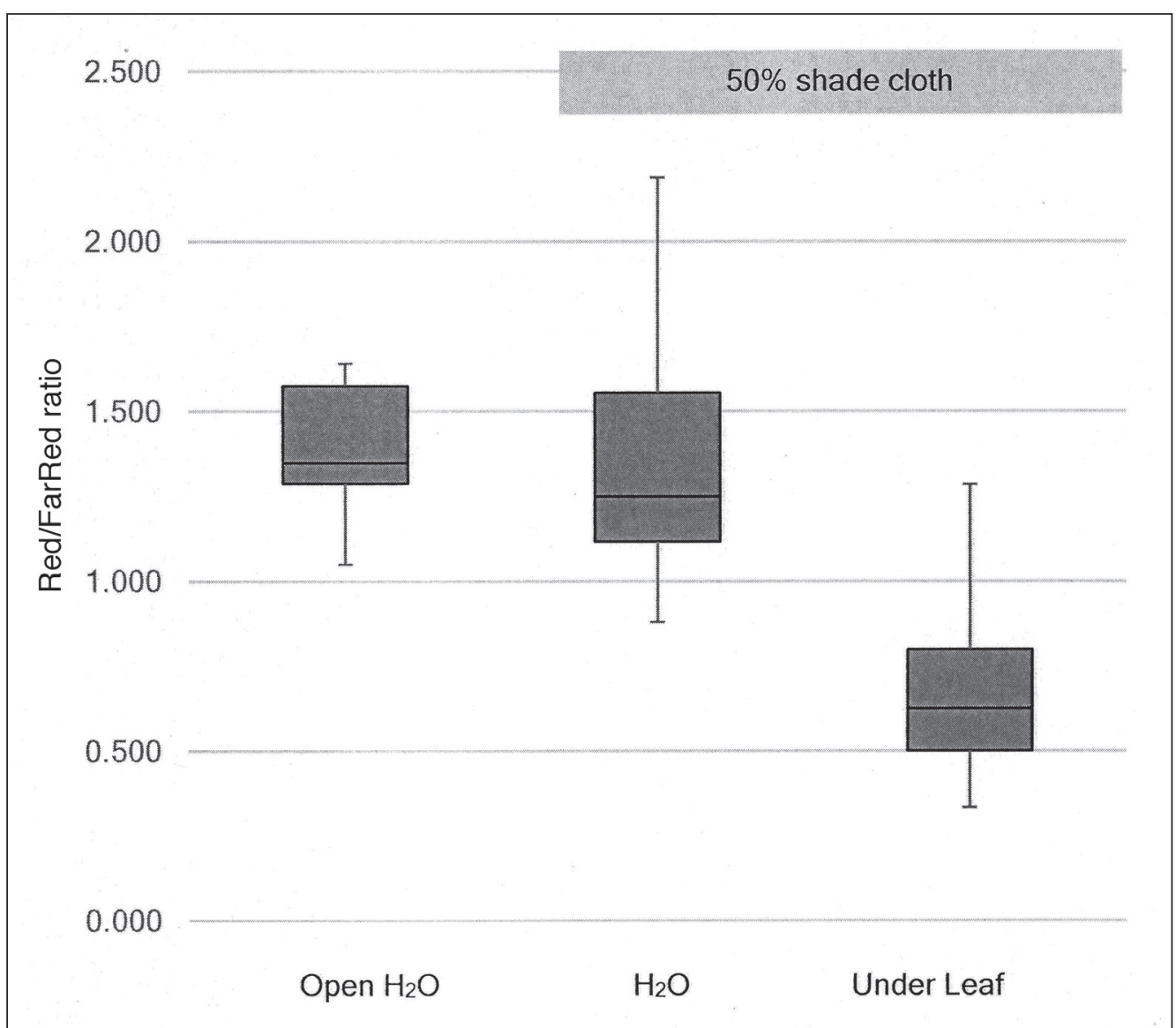

Figure 3. Underwater measures of red/far-red ratios in experimental tanks. All measurements were taken $\sim 40 \mathrm{~cm}$ below the surface of the water. Values under the leaf were taken at approximately the same depth, at the level of the rhizome, and thus are a measure of the light after passing through the leaf. Shaded bar represents treatments with $50 \%$ shade cloth. 


\section{Aerial leaf production}

No aerial leaves were observed in any of the tanks during field season 1, regardless of plant density or the presence of shade cloth. In field season 2, aerial leaves were produced in 7 of the 16 tanks. Aerial leaf production was not random; aerial leaves were more often found in high-density ( 5 plants) tanks ( 6 of 8 ) than in lowdensity (2 plants) tanks ( 1 of 8 ) (goodness-of-fit test: $\chi^{2}=6.34$, df $=1, P=0.01174$ ). Regardless of treatment combination, aerial leaves were produced in tanks where the mean maximum leaf cover (\%) was significantly higher (with aerial leaves = $42.7 \%$, S.D. $=2.3$; no aerial leaves $21.9 \%$, S.D. $=2.4$; $t$-test assuming equal variances: $t=12.6572$, df $=14, P<0.0001)$. Accordingly, surface-area coverage was strongly influenced by the density of plants in the tanks $\left(F_{1,12}=11.1097, P=0.006\right)$, with high-density tanks having 60\% more coverage than low-density tanks (highdensity mean $=40.2 \%[\mathrm{SD}=10.61]$, low-density mean $=24.7 \%[\mathrm{SD}=8.58])$. The presence of other plants had no significant effect on aerial leaf production $\left(F_{1,12}=\right.$ $0.3557, P=0.5620)$, nor was the interaction between density and the presence of other plants significant $\left(F_{1,12}=2.5786, P=0.1343\right)$.

There was a clear and not surprising relationship between the number of surface leaves and the percentage of leaf cover (Pearson's $r=0.8811, P<0.0001$; Fig. 5), and there appears to be a threshold value of leaf cover required to induce aerial leaf

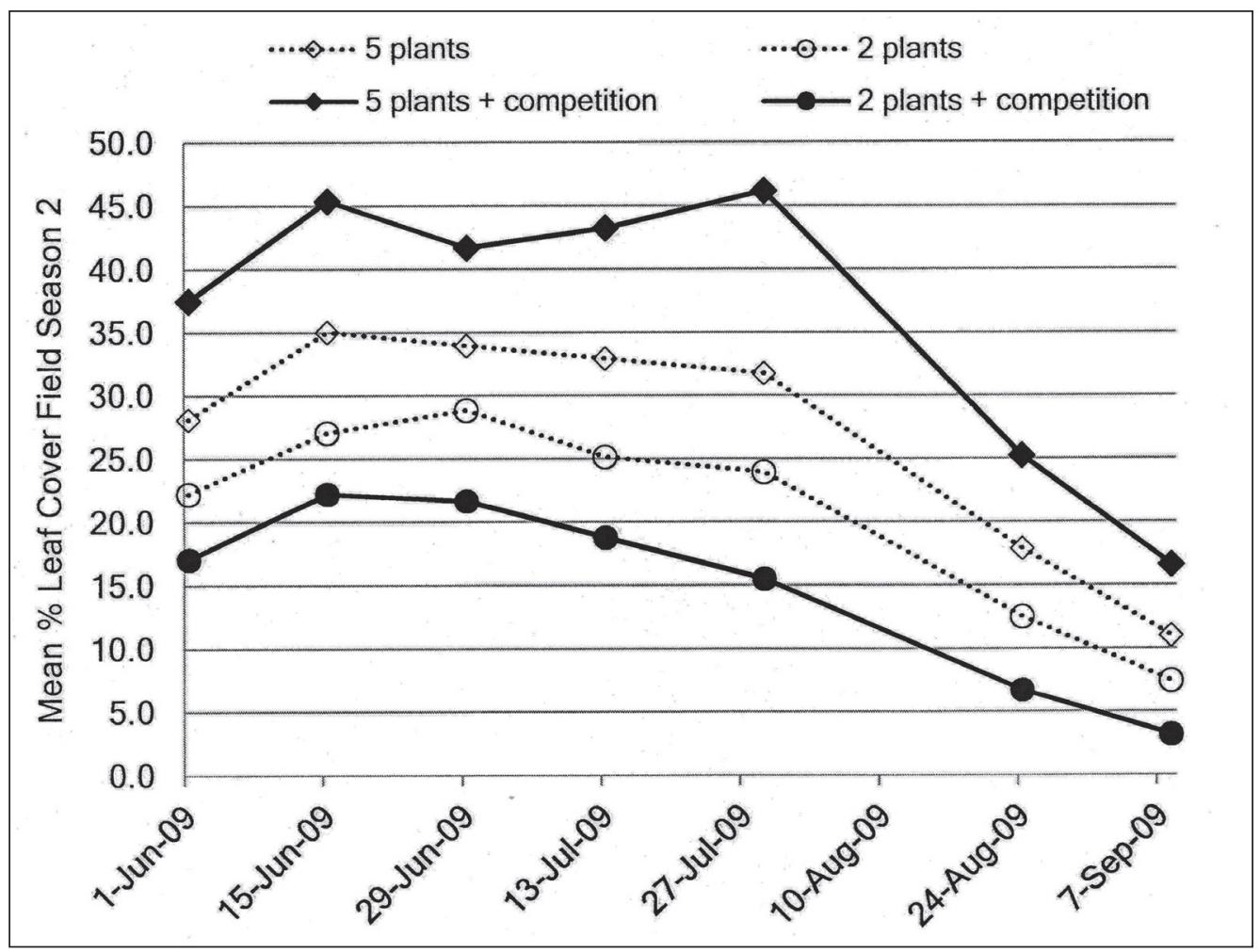

Figure 4. Mean percent cover of surface water with lily pad leaves among treatments with 5 or 2 plants per tank during field season 2. Treatments were either with (+ competition) or without competing algae. Standard deviations were omitted for visual clarity. 
production. Aerial leaves were produced only in tanks with $>40 \%$ surface coverage (Figs. 5, 6). As we noted above, no aerial leaves were produced during field season 1 , and only 1 of the 24 tanks had a surface area coverage of $>40 \%$ for more than 1

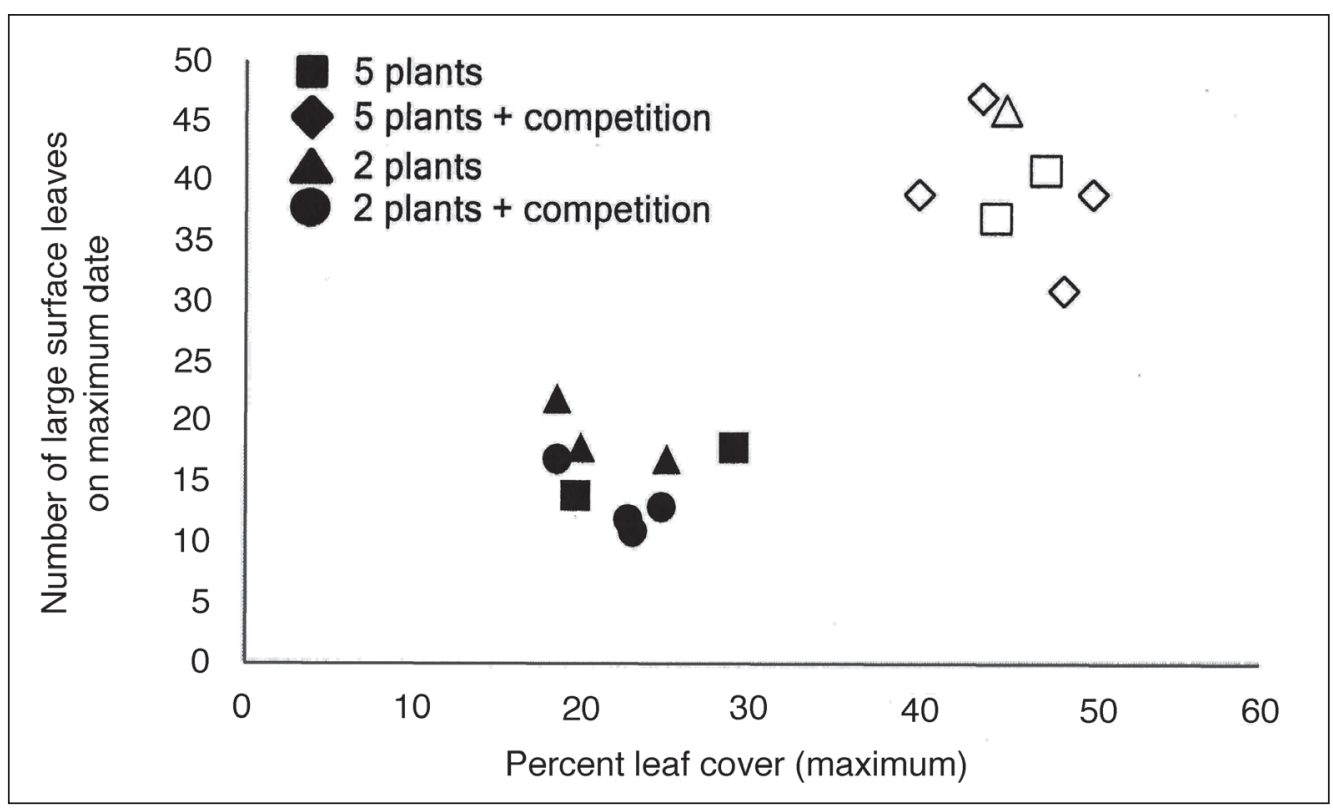

Figure 5. Relationship between the mean number of large surface leaves and the maximum percent leaf cover during field season 2. Filled symbols represent treatments where no aerial leaves were observed; open symbols represent treatments were aerial leaves were recorded.

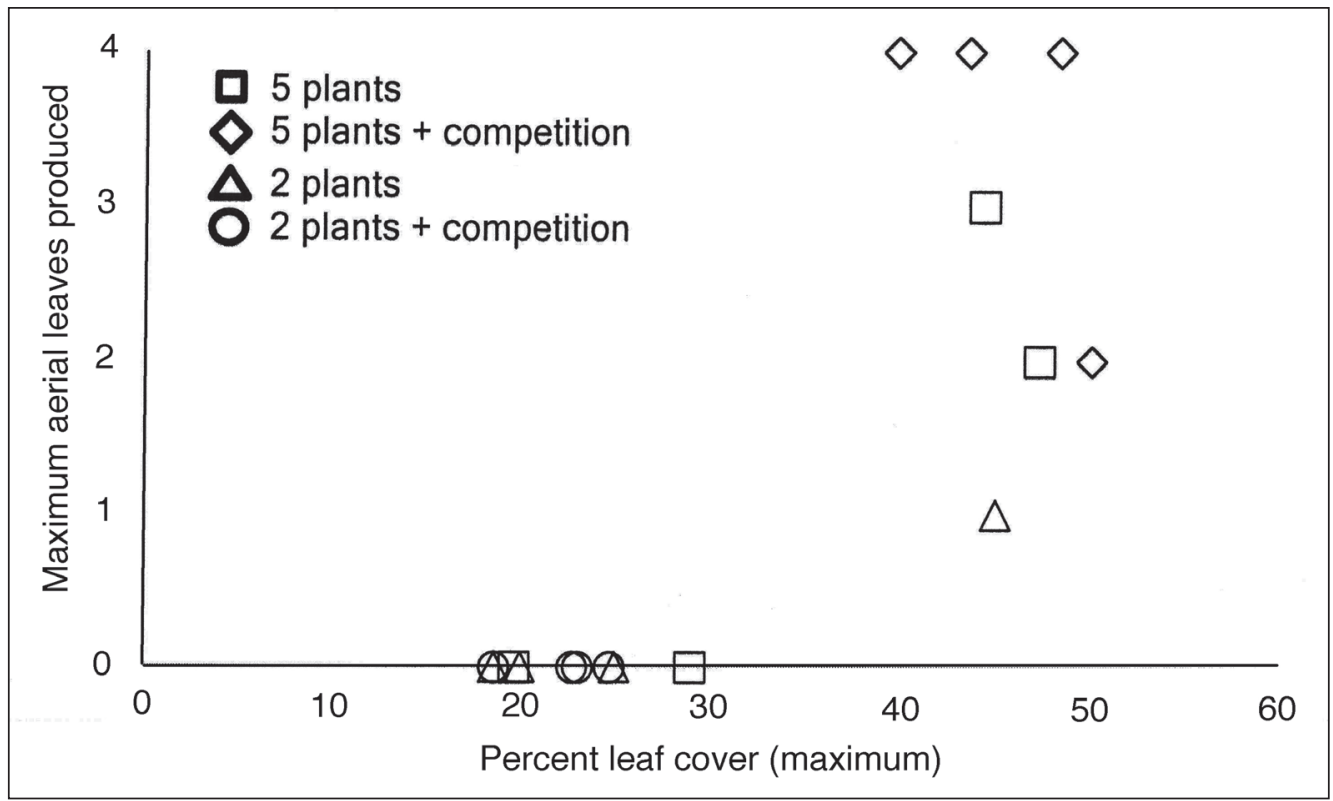

Figure 6. Maximum number of aerial leaves produced in a given treatment relative to the maximum percent leaf cover during field season 2 . 
observation period. In the second field season, 6 of the 7 tanks that produced aerial leaves showed $>40 \%$ leaf coverage for more than 1 month.

\section{Discussion}

In this study, we tested the hypothesis that changes in the underwater light environment stimulate the production of aerial leaves in American White Water Lily. The results from field season 1 strongly suggest that changes in light intensity alone are not a sufficient cue, as a 50\% reduction in light intensity (by way of shade cloth) was not enough to induce the appearance of aerial leaves. Somewhat surprisingly, the presence of the shade cloth served to modestly increase leaf production and subsequent leaf-coverage in tanks. In contrast, the results from field season 2 suggest that changes in light quality (red/far-red ratio) are a more reliable signal for the heterophyllic response in water lilies.

We suggest that water lilies use changes in the red/far-red ratio to monitor the competition for light, such that aerial leaves are produced when leaf cover is high, but surface leaves are produced when leaf cover is low, which occurs at both the beginning and the end of the growing season (Villani and Etnier 2008). While there may be other density-dependent environmental cues involved, the changes in leaf cover and subsequent changes in the red/far-red ratio correspond well with the patterns we observed in both natural and artificial settings. As light passes through a leaf, the red/far-red ratio decreases due to differential absorption of red and far-red light. When leaf cover is low, unfiltered light will penetrate the water to the developing rhizome during part or all of the day, as the sun moves across the sky. In contrast, as leaf cover increases, the developing rhizome will be exposed to longer periods of time in which the red/far-red ratio is decreased. As the surface cover of shading plants increases, more and more of the underwater environment will become red-light-depleted as those wavelengths are absorbed by the leaf canopy. Thus, as the surface area of a pond becomes covered with a canopy of leaves, water lilies produce aerial leaves that rise above the surface of the water. In field season 2 , aerial leaves were produced in tanks in which there was more biotic shading. We suggest that $\sim 40 \%$ cover by the water lily surface leaves (Fig. 4) may represent the minimal signal necessary to produce aerial leaves. The absence of aerial leaves during field season 1, despite briefly reaching higher surface leaf cover, suggests that there may be a temporal threshold which would be worthy of further investigation.

The aerial leaves, which rise above the existing surface leaf canopy, may allow water lilies to increase their photosynthetic capabilities when there is a canopy of leaves on the surface of the water. Similarly, the water lily could respond in the same manner if there was a heavy layer of algae or other competing plants. As the surface leaves naturally decay over the course of the growing season, the red/ far-red ratios will be less affected, and then aerial leaves will no longer be produced. Based on this hypothesis, aerial leaves will be produced only when there is sufficient density of surface leaf cover, suggesting that they may be unnecessarily costly to build or too expensive to maintain when light quality is not limiting. This strategy uses a light signal that is sensitive to any type of biotic surface cover, 
assuming it impacts the light quality in a significant manner. The exact impact is going to depend on the properties of the shading leaf in question, as a water lily leaf will potentially have greater impact than filamentous algae. Thus, this mechanism could initiate a response by lily plants to both intraspecific and interspecific competition, as well as self-shading.

The binary response of heterophylly in water lilies is determined early in leaf development in response to signals that occur well before an actual leaf is visible as a discrete structure on the plant (Villani and Etnier 2008). Thus, there is a time lag associated with the signal being received and the ultimate response of the plant, as seen in the delayed appearance of aerial leaves as leaf cover increases during the growing season (P.J. Villani and S.A. Etnier, pers. observ.). As there are potential costs to both types of leaves (e.g., changes in herbivory patterns [Kouki 1993], desiccation, etc.), we predict that this strategy allows lily plants to adjust leaf-growth patterns to maximize photosynthetic capabilities, while also potentially minimizing unwanted costs due to growing a poorly adapted leaf form.

Shade-induced decreases in the red/far-red ratio are commonly used by plants as an indicator of shading and the competition for light (Goliber and Feldman 1989, Leyser and Day 2003, Lin and Yang 1999, Schmidt and Milington 1968). Typically, plants grow long and spindly (etiolation) with increased lamina area when light is limited (Holbrook et al. 1991, Leyser and Day 2003, Smith 1982). In contrast, water lilies produce a robust petiole that allows the leaf to rise above the water's surface due to increased cross-sectional area (Etnier and Villani 2007), but petiole length and lamina area do not increase (Villani and Etnier 2008). In some types of plants, increases in far-red light also inhibit leaf expansion (Taylor and Davies 1988). As aerial leaves grow up through the water column, the leaf lamina of water lilies stays tightly wrapped in a cone-shaped structure, expanding only when the aerial leaf pushes above the water's surface (S.A. Etnier and P.J. Villani, unpubl. data). This coneshaped lamina may make it easier for the growing leaf to actually penetrate through the surface canopy and reach above the level of the water. As typified by shade-avoidance mechanisms in most flowering plants (Franklin 2008), this suite of responses in water lilies is likely phytochrome-mediated, allowing them to respond to the competition for light. Importantly, the overall response in water lily plants is quite different from the typical shade response that has been well-studied in both aquatic and terrestrial systems (Franklin 2008, Vandenbussche et al. 2005) and thus presents interesting questions about heterophylly and phytochrome signaling in water lilies.

\section{Acknowledgments}

The authors thank C. Bowman for his invaluable assistance in data and chigger collection, Dr. E. Gerecke for critical review of the manuscript, and The Butler Institute for Research and Scholarship at Butler University for funding of this project.

\section{Literature Cited}

Anderson, L.W.J. 1982. Effects of abscisic acid on growth and leaf development in American Pondweed (Potamageton nodosus Poir.). Aquatic Botany 13:29-44. 
Bristow, J.M. 1969. The effect of carbon dioxide on the growth and development of amphibious plants. Canadian Journal of Botany 47:1803-1807.

Deschamp, P.A., and T.J. Cooke. 1984. Causal mechanisms of leaf dimorphism in the aquatic angiosperm Callitriche heterophylla. American Journal of Botany 71:319-329.

Etnier, S.A., and P.J. Villani. 2007. Differences in mechanical and structural properties of surface and aerial petioles of the aquatic plant Nymphaea odorata subsp. tuberosa (Nymphaeaceae). American Journal of Botany 94:1067-1072.

Franklin, K.A. 2008. Shade avoidance. New Phytologist 179:930-944.

Goliber, T.E., and L.J. Feldman. 1989. Osmotic stress, endogenous abscisic acid, and the control of leaf morphology in Hippuris vulgaris L. Plant Cell and Environment 12:163-171.

Holbrook, N.M., M.W. Denny, and M.A.R. Koehl. 1991. Intertidal "trees": Consequences of aggregation on the mechanical and photosynthetic properties of sea-palms, Postelsia palmaeformis Ruprecht. Journal of Experimental and Marine Biological Ecology 146:39-67.

Johnson M. P. 1967. Temperature dependent leaf morphogenesis in Ranunculus flabellaris. Nature 214:1354-1355.

Kouki, J. 1993. Herbivory modifies the production of different leaf types in the Yellow Water-Lily, Nuphar lutea (Nymphaeaceae). Functional Ecology 7:21-26.

Kuwabara, A., K. Ikegami, T. Koshiba, and T. Nagata. 2003. Effects of ethylene and abscisic acid upon heterophylly in Ludwigia arculata (Onagraceae). Planta 217:880-887.

Leyser, O., and S. Day. 2003. Mechanisms in Plant Development. John Wiley and Sons, Blackwell, Oxford, UK. Pp. 138-161.

Lin, B., and W. Yang. 1999. Blue light and abscisic acid independently induce heterophyllous switch in Marsilea quadrifolia. Plant Physiology 119:429-434.

Monroe, K. and A.G.B. Poore. 2005. Light quantity and quality induce shade-avoiding plasticity in a marine macroalga. Journal of Evolutionary Biology 18:426-435.

Salles, S., J. Aquilera, and F.L. Figueroa. 1995. Light field in algal canopies: Changes in spectral light ratios and growth of Porphyra leucosticte Thur. in Le Jol. Scientia Marina 60:29-38.

Schmidt, B.L., and W.F. Millington. 1968. Regulation of leaf shape in Proserpinaca palustris. Bulletin of the Torrey Botanical Club 95:264-286.

Sculthorpe, C.D. 1967. The Biology of Aquatic Vascular Plants. St. Martin's Press, New York, NY. Pp. 120-150.

Smith, H. 1982. Light quality, photoperception, and plant strategy. Annual Review of Plant Physiology 33:481-518.

Smith, H., and G.C. Whitelam. 1997. The shade avoidance syndrome: Multiple responses mediated by multiple phytochromes. Plant, Cell, and Environment 20:840-844.

Taylor, G., and W.G. Davies. 1988. The influence of photosynthetically active radiation and simulated shadelight on the control of leaf growth of Betula and Acer. New Phytologist 108:393-398.

Vandenbussche, F., R. Pierik, F.F. Millenaar, L.A. Voesenek, and D. Van Der Straeten. 2005. Reaching out of the shade. Current Opinion in Plant Biology 8:462-468.

Villani, P.J., and S.A. Etnier. 2008. Natural history of heterophylly in Nymphaea odorata ssp. tuberosa (Nymphaeaceae). Northeastern Naturalist 15:177-188.

Wells, C.L., and M. Pigliucci. 2000. Adaptive phenotypic plasticity: The case of heterophylly in aquatic plants. Perspectives in Plant Ecology, Evolution and Systematics 3:1-18. 